\title{
Da boca suja à mente poluída: a carta de Cícero a Peto (Ad Fam. 9.22)
}

\author{
Lucas Consolin Dezotti \\ Universidade Federal da Paraíba (UFPB) \\ lucascdz@gmail.com
}

\begin{abstract}
RESUMO: Este trabalho apresenta uma tradução anotada da carta de Cícero a Lúcio Papínio Peto (Ad Fam. IX, 22). Nela Cícero disserta sobre a natureza e a origem da obscenidade expressa pela linguagem, recorrendo a exemplos práticos para demonstrar que o caráter obsceno de qualquer expressão linguística não se deve nem à natureza da coisa referida, nem à natureza da palavra pronunciada, e sim à atitude interpretativa do ouvinte. A tradução foi feita a partir do texto latino editado por Shackleton-Bailey (1977), acompanhado de notas explicativas para os exemplos utilizados por Cícero.
\end{abstract}

Palavras-chave: Cícero; obscenidade; cacofonia; uerecundia.

\section{Le caractère obscène des expressions linguistiques : la lettre de Cicéron a Paeto (Ad Fam. 9.22)}

RÉSUMÉ: Ce travail de recherche présente une traduction annotée de la lettre de Cicéron à L. Papinius Paeto (Ad Fam. IX, 22), dans laquelle Cicéron aborde la nature et l'origine de l'effet obscène exprimée par le langage. Il utilise des exemples pratiques pour démontrer que le caractère obscène de quelques expressions linguistiques ne relève pas de la nature de la chose référée ni de la nature des mots prononcés, mais de l'interprétation des auditeurs. Notre traduction a été faite sur l'édition de Shackleton-Bailey (1977), avec notes explicatives.

Mots-clés: Cicéron ; obscène ; cacophonie ; uerecundi 


\section{Introdução}

Quando se busca compreender as concepções antigas sobre a linguagem, um recurso comum são as grandes obras de retórica do período clássico e os tratados de gramática dos períodos tardios. Mas, além dessas obras específicas sobre o assunto, é possível encontrar informações dispersas, porém não menos importantes, em obras de outra natureza. Esse é o caso da carta de Cícero a Lúcio Papínio Peto, tradicionalmente catalogada como a $22^{\mathrm{a}}$ do livro IX das Epistulae ad Familiares.

Motivado pelo uso de uma palavra de baixo calão por Peto em carta anterior, Cícero responde com uma dissertação sobre o efeito de obscenidade expresso pela linguagem, a partir de duas noções antagônicas de adequação linguística: a "decência" (uerecundia), recomendada pela Academia platônica; e a "propriedade" (proprietas), recomendada pela doutrina estoica. Com base na análise de exemplos de uso, Cícero argumenta que o caráter obsceno de certas expressões linguísticas não se deve nem à natureza da coisa referida, nem à natureza da palavra pronunciada: o ouvinte é o responsável pela interpretação obscena.

A tradução a seguir foi feita com base no texto latino editado por Shackleton-Bailey (1977) e está acompanhada de comentários explicativos destinados a aproximar o leitor brasileiro desse antigo testemunho sobre a linguagem obscena.

\section{Texto Latino}

\section{INTER 46 ET 44(?) INCERTO}

\section{CICERO PAETO}

[1] Amo uerecundiam! - tu potius libertatem loquendi. atqui hoc Zenoni placuit, homini mehercule acuto, etsi Academiae nostrae cum eo magna rixa est. sed, ut dico, placet Stoicis suo quamque rem nomine appellare. sic enim disserunt, nihil esse obscenum, nihil turpe dictu; nam, si quod sit in obscenitate flagitium, id aut in re esse aut in uerbo; nihil esse tertium. in re non est. itaque non modo in comoediis res ipsa narratur (ut ille in Demiurgo "modo forte" - nosti canticum, meministi Roscium - "ita me destituit nudum": totus est sermo uerbis tectus, re impudentior) sed etiam in tragoediis. quid est enim illud "quae mulier una" - quid, inquam, est - "usurpat duplex cubile"? quid "huius tferei† hic cubile inire est ausus"? quid est "uirginem me quondam inuitam per uim uiolat Iuppiter"? bene "uiolat"; atqui idem significat, sed alterum nemo tulisset. uides igitur, cum eadem res sit, quia uerba non sint, nihil uideri turpe. ergo in re non est. 
[2] Multo minus in uerbis. si enim quod uerbo significatur id turpe non est, uerbum, quod significat, turpe esse non potest. "anum" appellas alieno nomine; cur non suo potius? si turpe est, ne alieno quidem; si non est, suo potius. caudam antiqui "penem" uocabant, ex quo est propter similitudinem "penicillus"; at hodie penis est in obscenis. at uero Piso ille Frugi in annalibus suis queritur adulescentis "peni deditos" esse. quod tu in epistula appellas suo nomine ille tectius "penem"; sed quia multi, factum est tam obscenum quam id uerbum quo tu usus es. quid quod uulgo dicitur "cum nos te uoluimus conuenire"? num obscenum est? memini in senatu disertum consularem ita eloqui: "hanc culpam maiorem an illam dicam?" potuit obscenius? "non", inquis; "non enim ita sensit". non ergo in uerbo est. docui autem in re non esse; nusquam igitur est.

[3] "Liberis dare operam" quam honeste dicitur; etiam patres rogant filios. eius operae nomen non audent dicere. Socraten fidibus docuit nobilissimus fidicen; is Connus uocitatus est. num id obscenum putas? cum loquimur "terni", nihil flagiti dicimus; at cum "bini", obscenum est? "Graecis quidem" inquies. nihil est ergo in uerbo, quoniam et ego Graece scio et tamen tibi dico "bini", idque tu facis quasi ego Graece non Latine dixerim. "ruta" et "menta" recte utrumque. uolo mentam pusillam ita appellare ut "rutulam": non licet. belle "tectoriola". dic ergo etiam "pauimenta" isto modo: non potes. uiden igitur nihil esse nisi ineptias, turpitudinem nec in uerbo esse nec in re, itaque nusquam esse?

[4] Igitur in uerbis honestis obscena ponimus. quid enim? non honestum uerbum est "diuisio"? at inest obscenum; cui respondet "intercapedo". num haec ergo obscena sunt? nos autem ridicule: si dicimus "ille patrem strangulauit", honorem non praefamur; sin de Aurelia aliquid aut Lollia, honos praefandus est. et quidem iam etiam non obscena uerba pro obscenis sunt. "battuit", inquit: impudenter; "depsit": multo impudentius. atqui neutrum est obscenum. stultorum plena sunt omnia. "testes" uerbum honestissimum in iudicio, alio loco non nimis. et honesti "colei Lanuuini", Cliternini non honesti. quid <quod> ipsa res modo honesta, modo turpis? suppedit, flagitium est; iam erit nudus in balneo, non reprehendes.

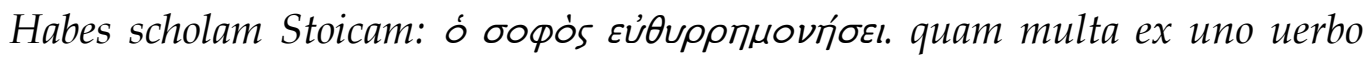
tuo! te aduersus me omnia audere gratum est; ego seruo et seruabo (sic enim adsueui) Platonis uerecundiam. itaque tectis uerbis ea ad te scripsi quae apertissimis agunt Stoici. sed illi etiam crepitus aiunt aeque liberos ac ructus esse oportere. honorem igitur Kalendis Martiis.

Tu me diliges et ualebis.

\section{Tradução}

Local incerto, entre 46 e 44 a.C. ${ }^{1}$

\footnotetext{
${ }^{1}$ NT: Segundo Otto E. Schmidt, é provável que esta carta tenha sido escrita em junho ou julho de 45 a.C., uma vez que "a argumentação é semelhante àquela exposta nos Academica II e no De finibus, entre outros, no sentido da oposição entre acadêmicos e estoicos" (SCHMIDT, 1893, p. 364).
} 


\section{CÍCERO [SAÚDA] PETO}

[1] Prezo muito a decência, já você, a liberdade de falar. Quem gostava era Zenão², homem agudo, sem dúvida, embora nossa Academia tenha uma grande rixa com ele... enfim, como eu dizia, os estoicos é que gostam de chamar cada coisa por seu nome. ${ }^{3} \mathrm{E}$ assim argumentam que nada é obsceno, nada é torpe de dizer. Ora, se a obscenidade provoca um certo escândalo, ou ele reside na matéria ou na palavra; não há terceira opção.

Na matéria não é, pois não só nas comédias essa matéria é mencionada (como no Demiurgo - "modo forte..." - você conhece a canção, lembra do Róscio ${ }^{5}$ " "ita me destituit nudum" - toda a fala foi encoberta por palavras, sendo bem indecente na matéria), mas também nas tragédias, pois o que seria aquele: "quae mulier una..." - aqui é o ponto - "usurpat duplex cubile?"7? E este: "huius Pherei hic cubile inire est ausus?" 8 . E este então: "uirginem me quondam inuitam per uim uiolat Iuppiter"9 - uiolat ("abusa") fica bem e significa o mesmo; já a outra palavra ninguém aceitaria. ${ }^{10}$ Assim, você vê que, embora a matéria seja a mesma, só porque as palavras não são, nada parece torpe. Logo, não está na matéria.

[2] Muito menos nas palavras. Pois se o que a palavra representa não é torpe, a palavra que o representa não pode ser torpe. Você chama o anus por um nome que não é dele. Por que não preferir o dele? Se é torpe, não adianta usar outro; se não é, melhor o dele. ${ }^{11}$

Os antigos chamavam a cauda de penis, daí, por semelhança, o pincel; mas hoje penis está entre as obscenas. É fato que o famoso Pisão Fruge se queixa em seus Anuários que os jovens são "escravos do pênis". O que você chama em

\footnotetext{
${ }^{2}$ NT: Zenão de Cítio, fundador da escola estoica.

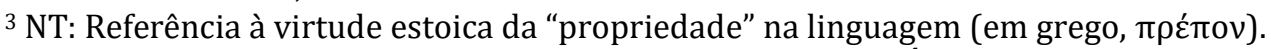

${ }^{4}$ NT: Nome de uma comédia de Turpílio, séc. II a.C. (MAGALLÓN GARCIA, 2008).

5 NT: Referência a Quinto Róscio Galo, ator de comédias contemporâneo de Cícero (MAGALLóN GARCIA, 2008).

${ }^{6}$ NT: "Logo agora...ela me deixou assim pelado"; a canção (canticum) era um monólogo cantado, em oposição ao diuerbium; aqui corresponde provavelmente ao solilóquio de um jovem que foi "depenado" pela meretriz (WILLIAMS, 1960, p. 266); em português, um duplo sentido semelhante poderia ser obtido com "ela me deixou duro desse jeito".

${ }^{7}$ NT: "Uma única mulher...que usufrui de dois leitos", provavelmente um trecho da Clitemnestra de Ácio, em que Electra reprova o comportamento sexual de sua mãe (WILLIAMS, 1960, p. 267).

${ }^{8}$ NT: "Ele ousou penetrar no leito de Feres", referência eufemística para o ato sexual; o verbo latino utilizado (inire, "penetrar") enfatiza a obscenidade.

${ }^{9}$ NT: "Júpiter usa a força para abusar de mim, ainda virgem, contra minha vontade", provavelmente um verso da Antíope de Pacúvio (WILLIAMS, 1960, p. 267).

${ }^{10}$ NT: A "outra palavra" é certamente o verbo futuĕre ("foder"), forma vulgar usada normalmente para se referir ao ato sexual entre homem e mulher, da perspectiva masculina (ADAMS, 1982).

${ }^{11}$ NT: Em latim, anus significa "argola", usado metaforicamente para evitar o nome culus ("cu").
} 
tua carta pelo nome, ele chama mais disfarçadamente de "pênis". Porém, como muitos usaram, já se tornou tão obscena quanto a palavra que você usou. ${ }^{12}$

E aquilo que é dito pelo povo, cum nos te uoluimus conuenire, também é obsceno? Lembro-me de um cônsul eloquente que falou assim no senado: hanc culpam maiorem an illam dicam? Poderia ser mais obsceno? "Não", você responde, "pois não foi isso que ele pensou". ${ }^{13}$ Logo, não está na palavra. E já mostrei que não está na matéria. Portanto, não está em lugar nenhum.

[3] Liberis dare operam ("esforçar-se para ter filhos"), como soa digno! E então os pais pedem aos filhos: o nome desse esforço não ousam dizer. ${ }^{14}$

Um lírico muito ilustre ensinou Sócrates a tocar lira: chamava-se Cono. Você acha isso obsceno? Quando falamos terni, não dizemos nada de escandaloso; mas se falamos bini, é obsceno. "Para os gregos, no caso", você vai dizer. Então nada disso está na palavra, já que eu também sei grego e mesmo assim digo bini a você, e é você que age como se eu tivesse falado grego, não latim. ${ }^{15}$

Ruta e menta estão ambas corretas. Quero falar "menta pequena" como falo rutula, não pode. Tectoriola é bonito; tente dizer pauimenta desse modo: não dá. Percebe então que não há nada além de bobagens, que a torpeza não está nem na palavra nem na matéria, e assim não está em lugar nenhum? ${ }^{16}$

[4] Portanto, somos nós que colocamos coisas obscenas em palavras dignas. Como assim? Diuisio, não é uma palavra digna? Mas dentro dela há uma obscenidade, que intercapedo também tem. ${ }^{17}$ Por isso essas palavras seriam obscenas? Já nós, que ridículo: se falamos ille patrem strangulauit "aquele estrangulou o pai", não dizemos "com todo o respeito"; já se falamos isso de

\footnotetext{
12 NT: Em latim, pincel é penicillum, diminutivo de penis; desta vez, o uso abusivo da metáfora fez perder o eufemismo; a propósito, é desta passagem que se infere que Peto teria usado a palavra mentula ("caralho") em carta anterior.

${ }^{13}$ NT: Nota-se aqui o cacófato produzido pelo encontro de vocábulos. No primeiro caso, a sequência cum nos soaria como cunnus ("buceta"), como o próprio Cícero explica alhures (cf. Orator, 154); no segundo, illam dicam soaria como landica ("clitóris"), vocábulo que aparece em poemas eróticos (e.g. Priapea 78). Na suposta reação de Peto ("não foi o que ele pensou") encontra-se a primeira referência à responsabilidade do ouvinte na interpretação obscena, algo que Quintiliano vai atribuir a todo cacófato: "considero que a culpa não é de quem escreve, mas de quem lê" (QUINT. Inst. VIII, 3, $45)$.

${ }^{14}$ NT: 0 nome vulgar do "esforço para fazer filhos", em latim, é futuĕre (cf. acima, n. 10).

15 NT: No primeiro caso, o nome grego "Cono" devia soar como cunnus (cf. acima, n. 13). No segundo, o vocábulo latino bini devia soar como uma forma de ßıvẽv ("foder"), igualmente vulgar. Note-se novamente a responsabilização do ouvinte pela interpretação obscena, desta vez com caráter bilíngue.

16 NT: Cícero lança mão da analogia, ao aplicar o sufixo de diminutivo (-ula) sobre dois pares de palavras dentro de um contexto estável: duas plantas aromáticas (ruta, "arruda"; menta, "menta") e dois termos ligados à edificação (tectorium, "cobertura"; pauimentum "calçada"). Se rutula e tectoriola não criam problemas, mentula e pauimentula soariam nitidamente obscenas (cf. acima, $\mathrm{n}$. 12).

17 NT: Este argumento se baseia num processo de segmentação: a palavra divisio contém um segmento que remete à palavra uisium ("cheiro podre"), no que se assemelha a intercapedo, cujo segmento pedo pode ser lido como verbo ("peidar").
} 
Aurélia ou Lólia, temos que dizer. ${ }^{18} \mathrm{E}$ sem dúvida também há palavras não obscenas usadas como obscenas. Um diz battuit ("furou"): indecente; outro depsit ("deu no couro"): muito mais indecente. Entretanto, nenhuma das duas é obscena. ${ }^{19}$

Tudo está repleto de tolices. A palavra testes é muito digna no tribunal, mas nem tanto em outro lugar. ${ }^{20}$ Os sacos em Lanúvio são dignos, em Clitérnia não. ${ }^{21}$ Como pode a mesma coisa ser ora digna, ora torpe? Ele peida, é um escândalo; se estiver pelado no banheiro, você não vai repreender. ${ }^{22}$ Você tem escola estóica: "o sábio falará de modo simples e direto". ${ }^{23}$

Quanta coisa de uma única palavra tua! Me agrada tua ousadia para comigo. Eu preservo e vou continuar preservando a decência de Platão, pois assim me acostumei. Por isso escrevi a você com palavras disfarçadas o que os estoicos fazem usando as mais explícitas. Mas eles também dizem ser conveniente que peidos e arrotos sejam igualmente livres. O respeito, portanto, nas calendas de março.

Continue gostando de mim, e fique bem.

\section{REFERÊNCIAS}

ADAMS, James N. The Latin sexual vocabulary. London: Duckworth, 1982.

KEIL, Heinrich. Grammatici Latini. 8 vols. Hildesheim: Georg Olms, 1961.

LIDDLE, Henry G.; SCOTT, Robert; JONES, Henry S. A Greek-English Lexicon. Oxford: Clarendon Press, 1996.

\footnotetext{
18 NT: Na primeira frase, strangulare é usado em sentido próprio, informando um parricídio; quando tem como objeto uma mulher, remete ao ato sexual, exigindo que o falante se expresse "com o perdão da palavra". 0 ridículo a que Cícero se refere parece ser o fato de que o código social não exige essa atitude de um parricida. Em tempo: é possível que Aurélia seja a esposa de Catilina e Lólia, a esposa de Aulo Gabínio, amigo de Clódio; ambos eram inimigos políticos de Cícero.

19 NT: Dois verbos em que Cícero identifica sentido obsceno: battuo pode significar "manejar a espada", daí a ideia de "furar", potencialmente obscena em português; depso é "curtir o couro", de onde se extrai facilmente a expressão "dar no couro", certamente obscena em português.

${ }^{20}$ NT: 0 argumento explora a homonímia da palavra testes ("testemunhas" e "testículos"). Ainda que Cícero aponte o contexto de fala como determinante do sentido, alguns séculos depois o gramático Sacerdote (KEIL, 1961, v. 6, p. 453) vai classificar como cacófato uma citação da oratória ciceroniana (In Verrem, II.2.139): teneat iam sane meos testis Metellus ("que Metelo tenha em mãos minhas testemunhas" - ou meus testículos?).

${ }^{21}$ NT: Uma possível explicação para este argumento é dada por J. Uría Varela (apud MAGALLÓN GARCIA, 2008, p. 108, n. 184), com base em uma referência de Festo (157.12), de que os habitantes de Lanúvio chamam os testículos de nebrundines, e por isso colei não seriam obscenos, ao passo que, em Clitérnia, coleus ("saco") teria o mesmo sentido que em português.

${ }^{22}$ NT: A resposta para a ambiguidade, que serve de conclusão, relaciona a ideia de adequação com o contexto de uso, explicitando a dimensão ética que permeia toda a discussão.

${ }^{23}$ NT: Frase atribuída a Zenão (frg. 1.22, cf. LIDDLE; SCOTT; JONES, 1996, p. 716).
} 
MAGALlÓN GARCÍA, Ana-Isabel. Marco Tulio Cicerón: Cartas a los familiares, vol. 2. Madrid: Editorial Gredos, 2008.

SCHMIDT, Otto Eduard. Der Briefwechsel des M. Tullius Cicero von seinem Prokonsulat in Cilicien bis zu Caesars Ermordung. Leipzig: Druck und Verlag von B. G. Teubner, 1893. Disponível em: https://archive.org/details /derbriefwechseld00schmuoft/page/364. Acesso em: 30 set.2020.

SHACKLETON-BAILEY, David R. (ed.). Cicero: Epistulae ad Familiares. Cambridge, Cambridge University Press, 1977. Disponível em: <https://latin.packhum.org/loc/474/56/175/80-93@1\#175>. Acesso em: 30 set.2020.

WILLIAMS, W. Glynn (trans.). Cicero: Letters to his friends. London: William Heinemann; Cambridge, Mass.: Harvard University Press, 1960.

Data de envio: 01/10/2020

Data de aprovação: 22/11/2020

Data de publicação: 21/12/2020 